\title{
La motivación para el aprendizaje de segundas lenguas minorizadas: el caso del estudio de la lengua náhuatl por universitarios hispanohablantes ${ }^{1}$
}

\author{
The motivation for learning minority second languages: \\ Spanish-speaking university students who study the Nahuatl \\ language
}

DOI: https://doi.org/10.32870/dse.v0i23.780

Miguel Figueroa-Saavedra*

\begin{abstract}
Resumen
Este artículo presenta un estudio sobre las motivaciones de hablantes de lenguas hegemónicas para aprender segundas lenguas minorizadas, centrándose en el caso de la lengua náhuatl. Se analizaron dos situaciones: una donde el náhuatl es considerado una lengua extranjera y en otra una lengua nacional, para identificar la asociación de motivos con determinados contextos. Los resultados muestran que los motivos instrumentales tienen mayor peso que los integradores, aun predominando factores intrínsecos. Esto es así porque el náhuatl no se visibiliza o percibe como una lengua hablada en el contexto social y académico del aprendiente, y porque las ideologías lingüísticas hispanocéntricas predominantes tienden a remarcar su valor en su sentido histórico o ideológico nacionalista, de modo que la orientación integradora responde más al deseo de incorporarse a una comunidad imaginada nacional o profesional que a querer contactar o ser parte de la comunidad nahua. Por tanto, el aprendiente valora el aprendizaje del náhuatl más como conocimiento que como medio de comunicación o integración.
\end{abstract}

Palabras clave: aprendizaje de segunda lengua - lengua minorizada - motivación - multilingüismo - náhuatl.

\begin{abstract}
This article presents a study on the motivations of hegemonic language speakers to learn minority second languages, focusing on the case of the Nahuatl language. Two situations, one in which Nahuatl is regarded as a foreign language and another where it is seen as a national language, were analyzed to identify the association of motives with certain contexts. The results reveal that instrumental motives have greater weight than integrative ones, even when intrinsic factors predominate. This is so because Nahuatl is not
\end{abstract}

1 Este artículo es parte de los resultados derivados del proyecto de investigación "In ichikawaltilis in nawanemilistli ipan in weyitetlamachtilistli inik tlahtolkuepalistli iwan tlahtolihkuilolistli ika nawatlahtolli. 2pan Tlakxitl" (DGI 33238201862), Instituto de Investigaciones en Educación, Universidad Veracruzana.

* Doctor en Antropología social. Profesor investigador en el Instituto de Investigaciones en Educación, Universidad Veracruzana, México. migfigueroa@uv.mx 
seen or perceived as a spoken language in the learners' social and academic context, and because the predominant Hispano-centric linguistic ideologies tend to highlight its value in a historical or nationalist ideological way. Thus, the integrative orientation responds more to a desire to join an imagined national or professional community rather than getting in touch with the Nahua community or being part of it. Learning Nahuatl is therefore seen more as acquiring knowledge than as a means of communication or integration.

Keywords: second language learning - minorized language - motivation - multilingualism -Nahuatl.

\section{Introducción}

Los estudios sobre la motivación para aprender una segunda lengua (L2) han tratado siempre de esclarecer las razones por las que las personas se animan a estudiar una lengua y finalmente toman esta decisión. Igualmente, han buscado saber por qué eligen una y no otra. En ocasiones este proceso se considera decisivo para predecir si se logrará aprender y dominar una $L 2$, pero, al margen de la preocupación pedagógica que esté en el fondo de este objetivo, esta elección no es un aspecto del cual se desprendan meramente cuestiones relacionadas con objetivos didácticos o logros curriculares. Esta decisión está marcada por contextos sociales y educativos que hacen que la motivación y elección reflejen una determinada situación sociolingüística bajo la cual el estudiante actúa. Así, en circunstancias y situaciones en las que el estudiante puede hacer un ejercicio de libre elección, encontramos casos donde la motivación como factor determinante del éxito en el aprendizaje de una $L 2$ tiene mayor relevancia, no solo desde un punto de vista personal y psicológico, sino comunitario y sociolingüístico.

Determinar las motivaciones para el estudio de una L2 supone atender al marco sociopolítico que envuelve al aprendiente como sujeto social y miembro de una comunidad lingüística. Desde esta perspectiva social y cultural, se quiere entender por qué se elige aprender una determinada L2 sin presencia, apoyo, promoción o visibilidad como la de las lenguas de enseñanza escolar tradicional, ni valorarse en el mercado de trabajo, es decir, siendo una lengua minorizada (LM). Precisamente, el caso del estudio de la lengua náhuatl es idóneo por ser una LM objeto de valoraciones negativas y positivas diversas, que reflejan la situación marginada y estereotipada de las lenguas nativas en México a raíz de un proceso castellanizador y una ideología lingüicida (Heath, 1992; Barriga, 1995; Muñoz, 2009; Flores, 2017) que, al día de hoy, no logra del todo revertirse a pesar de que desde 2003 se cuenta con la Ley General de los Derechos Lingüísticos de los Pueblos Indígenas y diversas reformas educativas que potencian el estudio y uso de las lenguas indígenas nacionales.

Según el Censo de Población y Vivienda 2010, 1'544,968 personas de 5 años y más hablan náhuatl. Esto hace de la lengua náhuatl la L2 nacional más hablada de México después del español, y la primera lengua indígena muy por delante del maya yucateco. Además, es también la más extendida por el país, pues encontramos hablantes en 556 municipios, distribuidos en 
17 de los 32 estados que conforman la república mexicana. De ser una lengua hegemónica entre el siglo XIII y hasta mediados del XVIII, durante el siglo XIX empezó a ser desletrada y reducida al ámbito rural y a las clases sociales populares, y a atomizarse geográficamente, hasta encontrarse hoy en riesgo de desaparición. Aunque en México ha estado siempre asociada al esplendor cultural autóctono e idealizada como lengua originaria de la nación mexicana, frente a otras lenguas autóctonas, no se la ha incluido en los currículos educativos generales, salvo en el subsistema de educación indígena y en las universidades interculturales, pero no dirigida a población no indígena. En cuanto a la oferta educativa de náhuatl como $L 2$, se desarrolla ante todo como talleres o materias ocasionales en ciertas licenciaturas, o mayormente en el sector informal y no formal (Nava, 2021).

\section{Motivaciones para querer aprender una L2: acercamientos teóricos}

Si revisamos lo que hasta hoy han sido los estudios sobre motivación, este aspecto ha merecido atención en tanto que se considera el punto de partida necesario para el aprendizaje de una lengua. A principios del siglo XX, la aptitud del aprendiente era vista como el factor psicológico clave para el aprendizaje de una L2. Con él se explicaba tanto el desarrollo del deseo de aprender una L2 como el logro alcanzado en ella (Henmon, 1929). Sin embargo, la aptitud lingüística no cobra importancia si no se relaciona con otros aspectos propios de la persona y su entorno.

Durante el siglo pasado, los acercamientos desde la psicología social y educativa destacarán las variables afectivas (actitud, inclinaciones, ansiedad, motivación) como predictores del logro de la L2 (Gardner, 1985). Estos aspectos, centrados en el carácter o la personalidad, resaltaron la incidencia del entorno sobre la persona. Así, entre 1960 y 1970 se comenzó a prestar atención a la importancia de la motivación, asociada a factores ambientales. En los años setenta y ochenta, las consideraciones sociocontextuales se fijaron en aspectos como el estatus minoritario o mayoritario de los hablantes (Clément, 1986: 271, Noels et al., 2000: 58) para explicar el deseo y el logro. Gardner y Lambert (1972) veían en la relación del aprendiente con la lengua y la comunidad meta un aspecto social destacado, pues despertaba y facilitaba el deseo de aprender una L2. Esta motivación integradora, resultado o medio para introducirse o acercarse a una comunidad lingüística determinada, y la motivación instrumental, aquella que explica el aprendizaje de una lengua como una ventaja o mérito competitivo y competencial en sí, eran factores clave para aprender una L2. La motivación integradora (Gardner, 1985: 82-83), por su realce como estímulo para la determinación y el aprendizaje de una $L 2$, recibiría posteriormente mayor atención (véase Dörnyei, 2008: 82).

La motivación para aprender una L2 se basaría en factores intrínsecos y extrínsecos según la teoría de la autodeterminación (Deci, Ryan, 1985), pero también en ciertas orientaciones o atracciones que conforman la llamada integratividad (Gardner, Lambert, 1959, 1972). Aunque los intereses instrumentales e integradores aseguran avances en el aprendizaje de la L2, 
la orientación integradora no guarda necesariamente una correlación positiva con el manejo proficiente (Noels et al., 2000: 59) o las aptitudes. Clément y Kruidenier (1983) sostendrán que la influencia del medio social requiere una más precisa problematización. Ellos advirtieron que, en contextos multilingües, la orientación integradora aparece entre miembros de grupos dominantes. Así, en los casos observados los aprendientes compartían cuatro orientaciones: querer viajar, hacer amigos, ampliar sus conocimientos y orientaciones instrumentales, es decir, aquellas no asociadas al deseo de contactar o integrarse con el grupo nativo hablante de la L2. No obstante, este deseo de contactar e identificarse con miembros del grupo meta, considerado un aspecto determinante para el aprendizaje, parece no ser fundamental para el proceso motivacional si su relevancia se limita a contextos socioculturales específicos (Noels et al., 2000: 60). Esto supone que, haya o no razones profesionales o curriculares (instrumentales, extrínsecas o intrínsecas), los individuos abordan el aprendizaje de una L2 para integrarse en una determinada comunidad mediante el conocimiento, apropiación y uso de esa lengua, por lo que este proceso de aprendizaje deriva también en un proceso de integración o aculturación. Esto vincula la orientación integradora a los modelos de vitalidad etnolingüística y de contexto social (Clément, 1986, 1980), el modelo de aculturación (Schumann, 1986, 1978a, 1978b), la mencionada teoría de la autodeterminación, la teoría de los posibles yoes (Markus, Nurius, 1986) y la teoría de la comunicación intercultural (Byram, 1997; Dörnyei, 2008).

La teoría de la aculturación (véase Siegel, 2003: 187) emplea dos conceptos, distancia social y distancia psicológica, útiles para entender que las respuestas actitudinales desde principios internos o externos son claves para el deseo de acercarse al grupo de L2 en un contexto de contacto, no circunscrito a un aula. Así Schumann (1986, 1978b), a través de un modelo psicológico, destaca las características sociales de los grupos de L1 y L2, pues considera que este contexto, más allá de la motivación, determinaría la proficiencia en el aprendizaje de una L2 como efecto aculturador. Por tanto -y esto nos conduce a la teoría de la comunicación intercultural-, supone para el aprendiente una modificación de actitudes, conocimientos y conductas hacia los miembros hablantes nativos de la L2. Esta modificación o adaptación, manifiesta en la capacidad o predisposición al cambio, depende de la distancia social y psicológica entre el aprendiente y el grupo meta. Cuanto mayor sea la distancia, menor será el contacto con el grupo hablante de la L2 y menos apertura habrá hacia los estímulos que promuevan el acercamiento y el dominio de la L2 por el aprendiente.

Esta atención al entorno natural del aprendiente, inmerso en la comunidad de L2 y su cultura, y su necesidad de adaptación y aceptación, nos lleva a fenómenos como la acomodación lingüística (Beebe, 1988; Giles, 1977) y la construcción de la identidad etnolingüística (Giles et al., 1977; Giles, Johnson, 1981, 1987). También nos habla de procesos de reafirmación o transformación identitaria cultural, a partir del manejo de las lenguas como marcadores relevantes de pertenencia. Sin embargo, el concepto de vitalidad etnolingüística (Giles et al., 1977) tuvo 
un peso y un papel dentro del modelo del contexto social para explicar la atracción cultural y lingüística del grupo de L2. La vitalidad etnolingüística se define como la combinación de tres factores (estatus, peso demográfico y apoyo institucional) que hacen que cierto grupo cultural y lingüístico destaque frente a otros. Cuanta más vitalidad, mayores son sus posibilidades de permanecer y continuar como grupo diferenciado.

El modelo del contexto social de Clément (Giles, Byrne, 1982) se consideraría el modelo teórico más integrado para describir la motivación como elección. Así, dos procesos determinarían la motivación para aprender una L2 (Clément, 1986: 272): la frecuencia de contacto con el grupo de la $L 2$, y la vitalidad etnolingüística relativa al grupo de $L 1$ y al de L2. El primero se entiende como un proceso motivacional primario, asociado al concepto de integratividad, y como resolución del conflicto entre la orientación afectiva y el temor a la asimilación. El segundo, busca comprender la valoración del estatus de la lengua de cada uno de los grupos etnolingüísticos implicados. Su valoración se establecería por su grado de vitalidad, derivado de su peso demográfico, estatus socioeconómico y apoyo institucional (Giles et al., 1977). Este modelo trataría de explicar qué desata la motivación y cómo esta se transforma en un estímulo continuo para lograr aprender otra lengua. Otros estudios complementan la distinción integradora-instrumental de la motivación.

Deci y Ryan (1985), en su teoría de la autodeterminación, complementan esta distinción integradora-instrumental con otros dos tipos de motivación, extrínseca e intrínseca. La extrínseca se basa en estímulos externos a la actividad misma, mientras que la intrínseca sería un interés hacia la actividad per se. Hay que advertir que no son categóricamente diferentes, pues se vinculan en su continuum de autodeterminación (Noels et al., 2000: 60). Si entendemos autodeterminación como la capacidad de decidir voluntariamente qué y cómo hacer algo según el propio interés, comprenderemos que algunas conductas orientan su realización hacia la satisfacción de alcanzar ciertos estados y metas. Este impulso estaría determinado por la personalidad, biología, biografía y contexto de las personas. La interiorización de ambos tipos de motivación, por tanto, explican la determinación de la persona por obtener algo que juzga consecuente a su naturaleza e interés particular. En la motivación intrínseca esas necesidades se perciben como particulares, propias, casi diríamos innatas, y pretenden alcanzar el disfrute, la satisfacción o la superación a un nivel competencial. A tal respecto, la teoría de los posibles yoes (possible selves) de Markus y Nurius (1986) completa esta idea de desarrollo de la persona desde un ajuste a sus expectativas y deseos de participación social, junto con otras concepciones sobre autocognición y socialización. Los yoes son un repertorio de ideas individuales de lo que deberíamos llegar a ser, de lo que nos gustaría ser y de aquello en lo que tememos convertirnos; lo cual proporciona un vínculo conceptual entre cognición y motivación. Esto supone explicar cómo los individuos se comportarán ante la oportunidad, posibilidad o necesidad de aprender una L2. Esos posibles yoes son los componentes cognitivos de las esperanzas, temores, metas y ame- 
nazas que le dan especificidad a la motivación según la relevancia, significación, organización y dirección de la decisión y las conductas. Esto sugiere que estos posibles yoes funcionan como incentivos para la conducta futura (Markus, Nurius, 1986) y proporcionan un contexto evaluativo e interpretativo para el vigente punto de vista en la construcción del sujeto como hablante y la carga identitaria que conlleve.

El modelo de la autodeterminación explica esta complejidad como un proceso de negociación y experimentación de intereses y sanciones, socialmente promovidas, y de inclinaciones personales productivas y realizables. Vallerand et al. $(1992,1993)$ llegará a establecer una taxonomía de motivaciones intrínsecas: búsqueda de conocimiento (explorar y conocer nuevas cosas), búsqueda de realización (sentir el logro de metas y dominio de tareas), búsqueda de estimulación (excitación, gratificación en la ejecución, fruición estética, diversión). En cuanto a las motivaciones extrínsecas, se consideran aquellas acciones que persiguen ganar una recompensa o evitar un castigo. Esto no implica una falta de autodeterminación si los motivos están interiorizados en el autoconcepto de la persona. Igualmente, según sea menor o mayor su grado de autodeterminación o interiorización autodeterminada, se reconocen otros tres tipos: regulación externa (donde los motivos son ajenos a la persona y, por tanto, si ese incentivo cesa, termina la actividad), regulación introyectada (donde el motivo externo se asume como de interés o beneficio propio, pero no es elegido inicialmente por la persona), regulación identificada (donde la persona elige y se identifica con el motivo y lo asume por razones de relevancia o competencia personal) (Deci, Ryan, 1985; Vallerand, 1997). A este conjunto de motivaciones y regulaciones hay que añadir un estado amotivacional, entendido como la situación donde la gente no ve relación entre sus acciones y las consecuencias de estas, no logra establecer el motivo de su realización al juzgar que los factores que explican o justifican esa actividad están fuera de su control o reconocimiento. Puede darse falta de deseo, de estímulo y cese, lo que se relaciona con la llamada indefensión o impotencia aprendida (learned helplessness).

No obstante, estas intenciones, represiones o disuasiones, en el marco social no pueden deslindarse de la existencia de oportunidades y posibilidades de negociación en el encuentro con el otro. Esto nos lleva a la teoría de la comunicación intercultural, la cual nos ayuda a ubicar el proceso de desarrollo de competencias comunicativas en un contexto de conocimiento y reconocimiento mutuo de identidades culturales (Noels et al., 2011). El aprendizaje de una L2 implica desarrollar capacidades para gestionar y negociar flexiblemente los significados de nuestra identidad, sea para declararla o negarla, sea para mostrar desacuerdo a cómo es definida y concedida por el otro (Kim, 2007: 244). La lengua, como herramienta para alcanzar fines sociales y psicológicos, trata de servir para entender, definir y navegar entre identidades, facilitando con la comunicación un marco interpretativo recíproco. Así, es posible superar las incertidumbres explicativa y predictiva que genera el contacto con el otro, pero esto depende del desarrollo que las competencias lingüísticas y cognitivas procurarían, y también del desarrollo de com- 
petencias emotivas, que son las que crean las condiciones para el acercamiento y contacto. En este punto, surge el aspecto motivacional como resultado de una pluralidad de deseos hacia otras culturas: curiosidad profunda por el otro, deseo de conocer y aprender del otro, deseo de romper barreras culturales (Rodrigo, 1997: 16-18).

Esto entronca el impulso xenofílico resaltado desde el modelo sociocontextual y la construcción de identidades (Clément et al., 1994: 433; Dörnyei, 2008; Dörnyei, Ushioda, 2009; Gardner, Lambert, 1972: 132), siendo el aprendizaje de una L2 el medio para la integración de identidades interculturales. No se trata necesariamente de identidades definidas o nacionales, también son identidades globales e imaginadas las que guían las trayectorias de aprendizaje en sus comunidades de práctica (Lamb, 2009; Yashima, Zemuk-Nishide, 2008) y permiten al individuo ubicarse como un bicultural dinámico (Noels et al., 2011) o un generador de nuevas identidades, al buscar el aprendiente resolver conflictos y desafíos culturales, personales y colectivos.

Todos estos modelos muestran una preocupación por afirmarse empíricamente como estudios áulicos para esclarecer la relevancia y el peso de sus aspectos teóricos en la explicación y predicción del proceso de aprendizaje de segundas lenguas. Sin embargo, en este planteamiento, la localización de grupos de estudio, las lenguas seleccionadas como L2, como estudios de caso generan una visión parcial de lo que son los procesos de aprendizaje de una L2. Todos estos modelos y teorías parecen explicar suficientemente cómo es el proceso de atracción en el estudio de una lengua oficial, hegemónica, internacional o global por parte de hablantes de otras lenguas nacionales o internacionales, pero no permiten en los mismos términos entender o abordar la motivación para estudiar una LM, local, sin vitalidad real o aparente. Así, no dejan de centrarse en el mercado global de las lenguas y no se perciben otros fenómenos ligados al mercado local de la enseñanza y aprendizaje de lenguas minorizadas que se desarrolla simultánea y más frecuentemente.

Animar a empezar y continuar cualquier proceso de aprendizaje desde razones u obligaciones particulares, como señala la teoría de la autodeterminación, o intenciones integradoras o instrumentales, de acuerdo con la teoría sociocultural, no adquiere un verdadero sentido social -sociolingüístico- si el proceso de interiorización o de resistencia y rechazo no se relaciona con las presiones y criterios marcados por políticas del lenguaje que determinan prejuicios y actitudes negativas hacia la $L 2$. Incluso las variaciones del modelo de Vallerand, que permiten ver y entender de modo más complejo esta relación, requieren que se reconozca este contexto ideológico para explicar esta interiorización o reproducción de las racionalizaciones que justifican la decisión de estudiar una LM. Dado que no se quiere esclarecer la relación que la motivación guarda con la proficiencia, sino con la superación, perpetuación o creación de prejuicios lingüísticos, habría que ahondar en la problematización de la influencia del medio social en esa dimensión de la conducta como práctica social, pues, por las razones señaladas, en los estudios efectuados se obvia o se neutraliza esta cuestión. Así, no se puede entender completamente lo que representa 
la motivación para aprender una L2 si solo se ven los casos donde el aprendiente es hablante de una L1 minoritaria y estudia una L2 mayoritaria (L1 local/nacional y L2 global/internacional), percibiendo el bilingüismo como un incuestionable incremento de valor comunicativo, social e intercultural. En cambio, queda por profundizar en los casos donde el aprendiente habla una L1 dominante y quiere aprender una L2 minorizada (L1 nacional/internacional y L2 local) en contextos desmotivadores, donde además la realidad multilingüe se aprecia más como un monolingüismo subjetivo por la sistemática invisibilización pública, falta de promoción y oferta extracurricular u optativa de su formación. Esto lo evidencia Jeff Siegel (2003: 182) cuando afirma que son inusuales los estudios donde los hablantes de lenguas dominantes estudien una lengua minoritaria o minorizada, y en caso de realizarse, es más habitual que sea en contextos naturales y no áulicos.

En Europa, a partir del siglo XXI se han desarrollado estudios que tratan de abordar esta situación en contextos de minorización lingüística y centrados en la figura del sujeto neohablante (Ramallo, 2020: 233-234; Amorrortu et al., 2019) y la incidencia del contexto social y las ideologías lingüísticas como el imperialismo y el nacionalismo lingüístico monolingüista (Phillipson, 1992; Moreno, 2008). El estudio del interés por no hablantes nativos de aprender euskera, gallego, aragonés, corso, feraoés, frisón, galés, lemko o sami, entre otras, es un tema que ha despertado interés por su relación con las políticas lingüísticas y las posibilidades de revitalización. El sujeto neohablante, entendido como "toda persona que aprende un segundo idioma y hace un uso relevante del mismo" (Ramallo, 2020: 238), siendo ese segundo idioma una LM, tiene motivaciones diversas que en sí se manifiestan como una decisión constatable, sólida y perdurable, y que implica una ruptura total o parcial con un orden lingüístico establecido a través de su praxis comunicativa (2020: 250). Así, sus motivaciones implícitas y explícitas, instrumentales e integradoras, a veces responden "más a una autoconsideración imaginada por parte del sujeto neohablante, una suerte de interpelación ideológica que lo sitúa como posible salvador de una determinada lengua" (Ramallo, 2020: 250, referido a O'Rourke, Ramallo, 2018).

Sin embargo, el caso abordado muestra otras características que no permiten que sobre el aprendizaje de una lengua indígena necesariamente aflore un sujeto neohablante, definido como un agente de cambio que altere o subvierta el orden lingüístico minorizador y en conflicto, sumándose a la comunidad de habla minorizada (Ramallo, 2020: 239). La peculiaridad del sistema sociolingüístico mexicano, su política lingüística y el grado de marginalidad y de vitalidad etnolingüística percibida en y sobre las comunidades indígenas describen otros fenómenos y efectos, al igual que motivaciones. Así, en el contexto mexicano encontramos algún trabajo inicial sobre el tema, como la tesis elaborada por la investigadora nahua Yoltzi Nava Hernández (2021) acerca del aprendizaje de la lengua náhuatl en contextos urbanos. Enfocada al estudio de la oferta formativa de carácter no formal, es decir, desvinculada de un programa educativo y con poco o sin valor curricular, identifica motivaciones intrínsecas (adquirir nuevos 
aprendizajes, conocer y apreciar otras culturas, el gusto por aprender cosas nuevas y complejas), extrínsecas (requisito explícito, exigencia por el contexto, reconocimiento social o incentivo económico), instrumentales (requisito laboral o escolar, mudanza, uso aplicado) e integradoras (proximidad a una comunidad, conciencia histórica, autoadscripción) (2021: 139-159). Estas motivaciones, presentes en diferente proporción en una amplia variedad de aprendientes que quieren estudiar la lengua náhuatl, tienen en común ir a contracorriente de un imaginario y un mercado lingüísticos hegemónicos, aún incluso ante la falta de expectativas de poder o querer hablar con un nahuahablante.

Estos acercamientos al fenómeno del aprendizaje de una L2 minorizada por hablantes de lenguas hegemónicas y en contextos donde se incentiva el aprendizaje de otras lenguas de prestigio y dominantes, da a los aspectos motivacionales una dimensión más significativa, si cabe, al existir múltiples factores disuasores para tomar dicha elección. De por sí este tipo de estudios proporcionan insumos que cuestionan algunas de las asunciones hechas desde otros planteamientos teóricos, radicados o influidos por marcos de hegemonía lingüística que eluden la asimetría, desigualdad y discriminación lingüística como variables. Así, este trabajo quiere sumarse a estos acercamientos al lado oscuro del mercado de la enseñanza de las lenguas, ampliando lo que sabemos hacia el ámbito de los estudios superiores y su limitada oferta educativa de lenguas minorizadas.

\section{Objetivo}

Dada la necesidad de ir ahondando en las razones que impulsan a estudiar una LM como L2 y el desconocimiento sobre lo que lleva a los hispanohablantes a estudiar una lengua como el náhuatl, el objetivo de este estudio es identificar y definir tipológicamente las motivaciones y regulaciones que les impulsan a estudiarla, y a su vez, tratar de entender y explicar dichas razones en cuanto a ciertos contextos sociolingüísticos disuasores o favorecedores. Por ello, se tratará de identificar rasgos particulares en función de si el náhuatl es visto como una lengua minorizada nacional (LMN) o una lengua minorizada extranjera (LME). Por otra parte, nuestro interés se centra en la población estudiantil universitaria, dado que hacia ella se dirige la oferta educativa más formalizada de la enseñanza de esta lengua, y presenta condiciones para que se manifieste toda posibilidad de expectativas, pues se ofrece como cursos optativos o de libre elección. Por tanto, las preguntas que nos guían desde este planteamiento son: ¿Qué tipo de motivaciones impulsan a estudiar una LM como el náhuatl? ¿Qué variaciones presentan estas motivaciones en el hispanohablante, sea vista esta lengua mexicana como una lengua extranjera o nacional? ¿Afecta la cercanía o contacto del aprendiente con la comunidad de habla originaria a sus decisiones como expectativa o experiencia? En tal caso, ¿en esta decisión se considera o se manifiesta el hecho mismo de la minorización lingüística de la L2? A partir de abordar estas cuestiones se identificarán los siguientes aspectos como objetivos específicos:

Diólo ○os

sobre Educación 
- La variación de las motivaciones instrumentales o integradoras para aprender la lengua náhuatl como L2.

- Los factores intrínsecos y extrínsecos asociados que establecen su regulación en la elección de aprendizaje.

- Las diferencias observadas, según la lengua náhuatl se considere una lengua nacional o extranjera, y la distancia social y psicológica asignada.

- Las experiencias y concepciones ideológicas que desde la autodeterminación del aprendiente integra el estudio del náhuatl dentro de un contexto de justificación y aplicación de su conocimiento.

Todo ello nos ayudará a comprender el sentido de la elección y el carácter sociolingüístico de las motivaciones asociadas dentro de las diferentes corrientes teóricas que tratan de comprender el papel que desempeña la motivación en el aprendizaje de segundas lenguas, incluso en aquellas no mostradas socialmente como deseables o posibles de aprender, $y$ en este sentido, también en el mantenimiento de las lenguas minorizadas.

\section{Método}

Para dilucidar estas cuestiones se parte del abordaje de la investigación como un estudio de caso, dada su singularidad y por su pertenencia y relevancia para la problemática planteada, al ser la lengua náhuatl un ejemplo claro de LM cuya enseñanza formal es factible en determinadas condiciones y a la que el interesado puede acceder libremente. Esto supone ampliar algunas primeras aproximaciones que abundaron (Figueroa, 2007) en dicho tema sobre los estudiantes de náhuatl de Ciudad de México y de Madrid (España), pero no lo problematizaron totalmente en su dimensión global. Así, esos primeros resultados se ponen a dialogar con lo que nuevos aportes han obtenido entre 2015-2017 en la Universidad Veracruzana. Dado que en México este tipo de acercamientos no se han prodigado, el estudio de caso que se establece es de carácter exploratorio-analítico (Coller, 2005: 41-44), en tanto que se quiere dar cuenta de un fenómeno único y representativo de lo que es la motivación de aprendizaje de una L2 minorizada en contextos sociolingüísticamente minorizadores, y también contribuir a la reflexión teórica sobre ello, y en concreto sobre la enseñanza de la lengua náhuatl.

La suficiencia de la exploración se basa en el proceso extensivo de la recogida de información, dado que la construcción de los casos se establece entre dos geografías (México y España) y una temporalidad que va de 2007 a 2017 en diversas instituciones, pues lo que quiere detectarse de modo exhaustivo son todos los posibles motivos hasta alcanzar la saturación teórica de acuerdo a su validez (Ruiz Olabuénaga, 2003), lo que ha justificado que en el caso mexicano se hayan incluido más grupos en diferentes etapas. Esto permite una descripción sistemática, objetiva y controlada de las características de los aprendientes como población, y de las motivaciones como área de interés (Colás, Buendía, 1998: 177). 
Para establecer los dos casos considerados de aprendizaje de la lengua náhuatl como LMN y como LME, se seleccionaron como muestra teórica las experiencias educativas bajo el criterio de ser una oferta educativa de lengua náhuatl impartida y avalada por una institución formal a estudiantes universitarios o titulados hispanohablantes. En el caso del náhuatl como LME, se consideró la enseñanza a universitarios ofrecida en el Museo de América de Madrid (grupo 1), participando 15 estudiantes. Para el caso del náhuatl como LMN se incluyó a la Licenciatura en Lengua y Literatura Hispánicas por su materia optativa de lengua náhuatl (grupo 3), participando 13 estudiantes. A estos datos se agregan otros obtenidos en dos instituciones mexicanas con materia optativa o de libre elección de lengua náhuatl, el Instituto de Investigación Filológicas y el Instituto de Investigaciones Antropológicas de la UNAM, con la participación de 41 estudiantes (grupo 2).

La recogida de información para su análisis se hizo sobre la base de un cuestionario general autoaplicado a los aprendientes, donde se les preguntaba datos sobre la ocupación o estudios que cursaban, lugar de procedencia, conocimientos que tenían de la lengua, cultura e historia de los nahuas, expectativas de aprendizaje, preferencias temáticas y razones para elegir cursar esta materia. Las preguntas estaban estructuradas y su respuesta era abierta. Con los grupos 1 y 2 , y para lograr una adecuada contextualización, también se entrevistó a los docentes responsables a fin de entender mejor la relación entre perfiles, tipos de motivación y situaciones personales y sociales. En el caso del grupo 3, como docente de este, se pudo realizar observación participante permitiendo una comprensión más amplia de las circunstancias, lo que facilitó una mayor profundidad interpretativa y analítica. En el caso del grupo 1, también se contó con aportes derivados del conocimiento del medio, las dinámicas y la población, al también haber sido docente de ese curso. Con estas diversas estrategias, puedo triangularse además la información a fin de lograr un control de calidad (Ruiz Olabuénaga, 2003) en el análisis descriptivo y explicativo de cada caso.

Los datos obtenidos permiten identificar una amplia variedad de motivos. Estos no se expresan como categorías excluyentes en el aprendiente, pues en ocasiones se manifiestan de modo agrupado en cada sujeto. En general se identifican razones más habituales, es decir, expresadas con mayor frecuencia que otras. No obstante, esta frecuencia no es significativa para el estudio pues responde a cuestiones coyunturales y no se analiza la preponderancia de tipos, solo su concurrencia. Así, su representatividad es teórica y no estadística, admitiendo cautamente limitaciones en la generalización de los resultados obtenidos (Ruiz Olabuénaga, 2003), pues este estudio adopta un enfoque prospectivo y centrado en una lengua y ámbito educativo particular.

Para su análisis descriptivo y explicativo, se procedió al registro de las respuestas y su categorización mediante las categorías teóricas clasificatorias ya definidas según su tipo de orientación (integradora-instrumental) y de regulación (externa, introyectada e identificada), para 
reconocer su variedad dentro de tales tipologías, y posteriormente, a relacionarse con sus situaciones socioeducativas, vivencia lingüística y contextos sociolingüísticos nacionales, para entender el sentido del impulso de satisfacer cierta necesidad o deseo de aprendizaje como una conducta social que adquiere su significación de acuerdo a una determinada situación sociolingüística asimétrica.

\section{Resultados: motivos para aprender la lengua náhuatl}

En general encontramos motivos recurrentes que los estudiantes muestran con diferentes razones para afirmar su decisión de estudiar lengua náhuatl. Se puede reconocer un primer conjunto de conocimiento lingüístico (conocer una lengua amerindia/conocer una lengua nacional) y que encontramos expresado como el deseo de conocer otras lenguas, sin más fin que ampliar su acervo idiomático. Puede dirigirse solo al sistema lingüístico en sí, expresados en afirmaciones como querer "conocer la lengua Náhuatl y su pronunciación" o "aprender y tener un acervo sobre el vocabulario", aunque esta "curiosidad por la lengua" también muestra una aspiración políglota por conocer la mayor cantidad de lenguas posible, primando lenguas poco conocidas o "exóticas", o cercanas y "propias". Así, alguno llega a afirmar que "tengo interés en conocer y aprender una lengua nacional, ya que no quisiera tener la mirada enfocada solo hacia lenguas extranjeras".

Hay un segundo conjunto de conocimiento antropológico o histórico-cultural (conocer la cosmovisión y cultura, conocer la tradición oral, conocer la historia) que lleva el conocer la lengua a un propósito aplicado, es decir, la lengua como medio para conocer el pasado y las características del pueblo nahua. Esto tiene una justificación etnográfica o antropológica lingüística como querer "alcanzar a saber como [sic] estructuran el pensamiento los pueblos de lengua Nahuatl [sic]", "comprender mi entorno cultural e histórico, el porqué de nuestras conductas", "conocer las bases del idioma y cómo sus vestigios siguen presentes", "aprender de la cultura de los antiguos", "poder comprender la lengua mucho mejor y entender un poco su contexto histórico", o simplemente porque "es una de las lenguas más importantes para descubrir culturas antiguas en nuestro país".

El estudio de la lengua o cultura náhuatl da paso a un conjunto literario-textual (aprender a leer y escribir, estudiar códices, traducir textos) que busca una aplicación más ligada a las habilidades de lectoescritura y a la cultura letrada y literaria nahua. Así, se quiere "conocer la lengua y adentrarme a la literatura e historia", "poder leer textos y entender más sobre la cultura mexicana", "aprender la lengua para poder hacer intentos de traducción de algunos textos", o, integrando los objetivos de los grupos anteriores, "iniciar en la lectura y escritura de náhuatl para poder investigar de manera posterior el pensamiento de los pueblos que hablan esta lengua". Evidentemente, en sí conocer una lengua se ve como parte de un conocimiento holístico, pero se estima que conocer la lengua náhuatl es "importante para la comprensión de la lengua y la literatura mexicana". 
A este sentido aplicado patente se suma un cuarto conjunto pragmático (completar mi formación, mejorar mi argumentación académica, cumplir los créditos) donde se destaca sobre todo el beneficio curricular y académico para completar su formación o simplemente concluir los estudios, buscando "cumplir con créditos de elección libre", cursarlo por "la relación que tiene con la antropología lingüística", lo que no deja de relacionarse con la idea de ampliar el conocimiento de lenguas, no para su estudio sino para mostrarlo como mérito.

Por último, hay un quinto conjunto relacional-identitario (trabajar en comunidades, pertenecer a la mexicanidad, ser de una comunidad) con un sentido más ideológico y personal que no deja de estar presente en los anteriores conjuntos bajo la expresión de lo mío/lo nuestro y que supone justificar la elección como un acercamiento a lo propio, de querer "conocer más mi cultura". Este propósito reivindicativo o apropiativo se justifica solo por el hecho de ser, porque "mi ascendencia es nahua", porque "de donde [sic] vengo [Sierra de Puebla] se habla la lengua y estoy familiarizada con ella", porque su "línea genealógica, de lado materno, es de origen Zapoteco, así considero necesario conocer mis raíces indígenas a través de la literatura de tradición oral", o porque "creo que las culturas indígenas, son nuestra verdadera cultura y lo demás son los intentos de los meztisos [sic] y los criollos por imitar a los otros países ricos". Evidentemente, estos pareceres expresan imaginarios y posturas ideológicas que habrá que contextualizar más adelante, pero que también expresan la adopción de un posicionamiento frente a un orden lingüístico que oculta y minoriza la lengua náhuatl como opción de estudio. Así, se quiere al menos una oportunidad para "reflexionar respecto a la revalorización e importancia de la lengua, la cultura y la literatura nahua".

Para poder contextualizar y explicar más adelante el valor sociocultural de estos motivos y contribuir al debate teórico sobre la motivación para aprender una L2, a continuación, se categorizan según la capacidad de decisión e intención para alcanzar un determinado estado o meta. En la tabla 1 se sintetizan los motivos señalados por los grupos estudiados ya descritos en el apartado anterior. Inicialmente, los motivos instrumentales (intrínsecos o extrínsecos) responden a necesidades surgidas de la práctica educativa o profesional, sea para su aplicación inmediata o futura. Así, ciertos motivos están muy ligados a la naturaleza de las carreras académicas o a la expectativa de lo que espera encontrarse en una optativa para una licenciatura de letras, de antropología o de americanística.

Es evidente que el entorno establece condiciones, referentes y regulaciones que hacen que el carácter de estas motivaciones no pueda fácilmente diferenciarse en sus dimensiones intrínsecas-extrínsecas e instrumentales-integradoras al interrelacionar intereses educativos, profesionales, personales y sociofamiliares. Por ello, en la tabla 2, se organizan las motivaciones expresadas por el grupo 3 según el modelo de autodeterminación de Deci y Ryan (1985), de manera que podamos entender los tipos de regulación de las motivaciones para el aprendizaje del náhuatl en un contexto determinado, y así poder mostrar cómo están interiorizadas. 
Tabla 1. Motivos instrumentales e integradores

\begin{tabular}{|c|c|c|c|}
\hline \multirow{2}{*}{ Motivación } & \multirow{2}{*}{$\begin{array}{l}\text { Caso LME } \\
\text { Grupo } 1\end{array}$} & \multicolumn{2}{|l|}{ Caso LMN } \\
\hline & & Grupo 2 & Grupo 3 \\
\hline \multirow{5}{*}{ Instrumental } & $\begin{array}{l}\text { Conocer lengua ame- } \\
\text { rindia }\end{array}$ & $\begin{array}{l}\text { Conocer lengua amerin- } \\
\text { dia }\end{array}$ & $\begin{array}{l}\text { Conocer lengua amerindia } \\
\text { Conocer lengua nacional }\end{array}$ \\
\hline & $\begin{array}{l}\text { Estudiar códices } \\
\text { Traducir textos }\end{array}$ & $\begin{array}{l}\text { Estudiar códices } \\
\text { Traducir textos }\end{array}$ & Aprender a leer y escribir \\
\hline & $\begin{array}{l}\text { Conocer la tradición } \\
\text { oral }\end{array}$ & & $\begin{array}{l}\text { Conocer historia y litera- } \\
\text { tura }\end{array}$ \\
\hline & $\begin{array}{l}\text { Conocer cosmovisión } \\
\text { y cultura }\end{array}$ & $\begin{array}{l}\text { Conocer cosmovisión y } \\
\text { cultura }\end{array}$ & $\begin{array}{l}\text { Conocer cosmovisión y } \\
\text { cultura }\end{array}$ \\
\hline & $\begin{array}{l}\text { Complementar mi } \\
\text { formación }\end{array}$ & $\begin{array}{l}\text { Complementar mi forma- } \\
\text { ción }\end{array}$ & $\begin{array}{l}\text { Mejorar mi argumentación } \\
\text { académica } \\
\text { Cumplir con los créditos }\end{array}$ \\
\hline Integradora & & $\begin{array}{l}\text { Trabajar en comunidades } \\
\text { Pertenecer a la mexica- } \\
\text { nidad }\end{array}$ & Ser de una comunidad \\
\hline
\end{tabular}

Fuente: elaboración propia.

Tabla 2. Motivaciones y regulaciones para estudiar náhuatl como L2

\begin{tabular}{|c|c|c|c|}
\hline Motivación & Regulación externa & Regulación introyectada & Regulación identificada \\
\hline \multirow[b]{2}{*}{ Instrumental } & \multirow{2}{*}{$\begin{array}{l}\text { - Cumplir créditos } \\
\text { - Argumentar tra- } \\
\text { bajos académicos }\end{array}$} & $\begin{array}{l}\text { - Argumentar trabajos aca- } \\
\text { démicos }\end{array}$ & \multirow{2}{*}{$\begin{array}{l}\text { - Conocer lengua amerin- } \\
\text { dia } \\
\text { - Hablar la lengua } \\
\text { - Escribir la lengua } \\
\text { - Leer la lengua } \\
\text { - Trabajar en una comuni- } \\
\text { dad }\end{array}$} \\
\hline & & $\begin{array}{l}\text { - Complementar formación: } \\
\text { Conocer su literatura e his- } \\
\text { toria } \\
\text { o Conocer y aprender lengua } \\
\text { amerindia } \\
\text { o Conocer historia de la len- } \\
\text { gua } \\
\text { oTraducir textos } \\
\text { o Estudiar códices } \\
\text { o Trabajar en una comunidad }\end{array}$ & \\
\hline Integradora & $\begin{array}{l}\text { - Conocer lengua } \\
\text { de estudio }\end{array}$ & $\begin{array}{l}\text { - Conocer lengua de estudio } \\
\text { - Conocer lengua nacional } \\
\text { - Conocer historia de la len- } \\
\text { gua }\end{array}$ & $\begin{array}{l}\text { - Conocer lengua de estu- } \\
\text { dio } \\
\text { - Conocer lengua nacional } \\
\text { - Conocer/Acceder cosmo- } \\
\text { visión y cultura } \\
\text { - Conocer lengua familiar / } \\
\text { ser de la comunidad } \\
\text { - Conocer historia de la } \\
\text { lengua } \\
\text { - Trabajar en una comuni- } \\
\text { dad } \\
\text { - Pertenecer a la mexica- } \\
\text { nidad }\end{array}$ \\
\hline
\end{tabular}

Fuente: elaboración propia. 
A continuación, se contextualiza esta tipología de acuerdo con el tipo de oferta educativa y perfiles de los estudiantes para comprender mejor cada una de las orientaciones motivacionales.

\section{Motivaciones instrumentales}

Respecto a las motivaciones instrumentales (tabla 1 y 2 ) y en lo referente a la regulación externa se aprecia que, al ser una elección opcional, no hay motivos que puedan considerarse "forzados" o predeterminados, aunque haya motivos que no responden a un interés por la lengua o el grupo meta, sino por satisfacer requisitos para la titulación. Esto revela una motivación extrínseca por estudiar esta optativa como una experiencia (considerada o no dentro del currículo) que enriquece la formación con un enfoque profesional o, en todo caso, sirve para completar los créditos que se requieren para egresar de la licenciatura. Aunque este motivo se ve aquí mencionado por el grupo 2, es un aliciente implícito y considerado. Incluso, en su momento el Museo de América gestionó que su curso tuviera el valor de un crédito como curso externo.

Por otro lado, se combina la curiosidad con la posibilidad de sacarle partido como un conocimiento que sirva para trabajos académicos e investigativos (saber de qué se habla, manejar adecuadamente términos de otra lengua, reconocer etimologías, corroborar traducciones) y el manejo de narraciones, fuentes históricas o grabaciones, además de saber escribirla. Esto se relaciona además con la importancia dada a la escrituridad y oralidad de la lengua en las carreras de Letras y Antropología, no siempre por razones extrínsecas.

También se manifiesta como regulación introyectada según idearios profesionales, por tanto, responden a aquello que establece un perfil deseable de formación de cara a la práctica profesional que asume el estudiante. Así, como se dijo, se considera este conocimiento para reforzar habilidades comunicativas argumentativas, pero no por sentirlo exigido, sino porque el estudiante lo considera una preparación para el ejercicio profesional y puede ser estimado en el mercado laboral. Así, se ve como un complemento formativo necesario que no está reconocido en la formación troncal, por lo que se siente obligado a cursarlo. Los estudiantes de historia, filosofía o antropología sienten que les ayuda a tener una mejor preparación en pensamiento, historia o cultura de México. Igualmente, los estudiantes de lingüística o literatura sienten que se logra un acercamiento más pleno a la literatura y lenguas de México o del mundo. Así también se verá como regulación identificada desde un planteamiento integrador y en un sentido vocacional, hay una motivación instrumental que ve en este aprendizaje un medio de profesionalización que preludia el llegar a ser reconocido como un licenciado formado adecuadamente en un campo específico. Esto se hace muy patente en carreras donde la cultura oral y escrita nahua es un objeto de estudio preestablecido.

Por esto, la motivación principal instrumental es la expectativa de aprender la lengua y así acceder a través de ella a la cultura nahua (pensamiento y lenguaje). Esto parece ser común a 
todos los grupos, con el detalle de que entre los aprendientes mexicanos aparece la etiqueta de lengua nacional, lo que da una dimensión muy particular que va a asociarse con motivaciones integradoras diferenciadas entre el caso mexicano y español como veremos. Es interesante notar que en su desarrollo como competencia lingüística, esta tiene en general más una orientación informativa que comunicativa, aunque pueda invertirse esta relación en algunas motivaciones integradoras. Por tanto, la visión de la lengua es muy objetual. Esto se refleja en una tendencia a verla como un medio y fin en sí para lograr un conocimiento particular más profundo.

\section{Motivaciones integradoras}

Respecto a las motivaciones integradoras (tabla 1 y 2), estas pueden derivar en su valoración como medio para sentirse o ser reconocidos como miembros de una comunidad de trabajo y pensamiento. Así, el conocer una lengua exótica o una lengua amerindia puede ser sentido como un acercamiento a un perfil de lingüista o experto de la lengua más completo. Por otra parte, y en esto pesa el contexto nacional, el aprendizaje de esta lengua se ve como un medio para sentirse uno más aceptado o integrado en un contexto donde se valore el conocimiento de esta lengua como un plus que le hace sentirse o ser reconocido como un ciudadano mexicano multicultural.

Así también puede haber un deseo de participar y ser parte de una comunidad nahuahablante, sea esa comunidad imaginada como el conjunto de la nación mexicana o identificada concretamente con la nación nahua o con alguna de sus comunidades, sino incluso su familia. Como señala Anderson, la construcción de una comunidad imaginada como "un organismo sociológico que se mueve periódicamente a través del tiempo homogéneo, vacío" (Anderson, 1993: 48) se ejemplifica en la idea de nación y en cualquier imaginario de vivencia colectiva que se conciba como algo sólido y reconocible. Por tanto, el conocimiento de la lengua y de la cultura del grupo meta a través de ella, se considera fundamental para poder ser o sentirse parte de esa u otra comunidad basada en la lengua.

Por tanto, estos motivos manifiestan dos dimensiones de experiencia: una profesional y una personal. La dimensión profesional puede ser en cierto modo predecible, pues responde sobre todo a ver en este aprendizaje el desarrollo de competencias comunicativas interculturales. Esta posibilidad también se ve muy condicionada a la previsión de experiencias de contacto con el grupo nahuahablante y depende por tanto de la distancia social del aprendiente, de ahí que en principio el grupo 1 no manifestara tal motivación al no estar esto en sus posibilidades y expectativas cercanas. Esto pareciera ser algo consustancial a ciertas carreras que ven en el trabajo de campo o la convivencia con la comunidad nahuahablante como una comunidad de aprendizaje, un objeto de estudio o un destino profesional. Sin embargo, como se verá más adelante, no siempre es así debido a la distancia psicológica y precisamente a las ideologías lingüísticas del grupo hispanohablante. 
Por otra parte, la dimensión personal introduce el aspecto más diferencial entre el grupo 1 y los grupos 2 y 3 , y se manifiesta de modo muy diferente entre estos, pero que nos dibuja un panorama de acción muy característico de la situación sociolingüística mexicana, pues, aunque responden a una orientación integradora, no es su objetivo ser parte del grupo nativohablante. A tal respecto, hay un conjunto de motivos muy asociados a la regulación identificada, pues no hay un modelo o estímulo institucional o un imaginario generalizado sobre las expectativas académicas o laborales que puede generar el estudio del náhuatl. Así, el acercamiento al conocimiento inicial o profundo de la lengua responde a inquietudes personales que ven en ello una ventaja personal $y$, sobre todo, una forma de encarnar un ideario de profesional o de persona ilustrada. Esto es más evidente al querer desarrollar habilidades de lectoescritura, dado que es una destreza que no suele exigirse, ni siquiera considerarse (precisamente el efecto minorizador hace ver al náhuatl como una lengua iletrada).

En los estudiantes de letras se hace esto patente al conferir un tratamiento de igualdad pues parten de la presuposición de que la lengua se escribe o debe escribirse, reconociendo que hay una producción literaria nahua. En cuanto a los estudiantes de antropología, algunos tienen el deseo de trabajar en comunidades y aunque "no sea necesario" el náhuatl en comunidades bilingües, sí consideran adecuado o ventajoso usarlo para tener una recogida de información amplia y de calidad.

Por tanto, pareciera que la autodeterminación del aprendiente por aprender la lengua tiene más que ver con identificarse que con integrarse. Pero estas cuestiones merecen verse más a fondo a un nivel interpretativo. Por tanto, se ahondará en los contextos e imaginarios sociolingüísticos que ayuden a entender las implicaciones teóricas de estas motivaciones instrumentales e integradoras por aprender una LM, tanto por ser una LME como una LMN.

\section{Discusión de resultados}

\section{El náhuatl como lengua nacional o extranjera}

Como cabría esperar y como se puede notar (tabla 1), hay diferencias entre cómo se percibe y por qué interesa aprender el náhuatl, sea esta vista como una LME o una LMN por los hispanohablantes. Es cierto que en España y México el náhuatl manifiesta una invisibilidad social, pero por diferentes causas. En España, el imperialismo lingüístico panhispánico ha prodigado una imagen uniformista de la lengua española, pero también uniformadora, frente a la diversidad lingüística. Así, la castellanización de Hispanoamérica como hito civilizatorio aplica una capa homogénea de hispanidad y modernidad que ha hecho que dicha diversidad sea imperceptible e incluso borrada (cfr. Moreno, 2015: 144-146), creándose la tautología o falacia de que Hispanoamérica es Hispanoamérica porque allí se habla español. Este imaginario hispanófono tiene su contraparte en el nacionalismo lingüístico mexicano, que también ha procedido igualmente a mostrar dentro y fuera de sus fronteras al país como una nación esencialmente hispanoha- 
blante, aunque esta representación en las últimas décadas se haya visto sometida a una revisión social y política. De cualquier modo, la existencia de lenguas americanas se ha enseñado como una característica regional "prehispánica", es decir, premoderna. La revelación de que estas lenguas siguen existiendo hace que en principio algunos hispanohablantes desmonten ciertos prejuicios lingüísticos que las creían extintas, inútiles, primitivas y vean interesante o necesario conocerlas, aprenderlas.

Sin embargo, en el caso español, la vaguedad de este reconocimiento no deja de sumergirse en otro imaginario derivado de una visión generalista y difusa (casi confusa) de ese otro americano como una comunidad imaginada unitaria de la indianidad, que reduce la diversidad y diferencia de las lenguas amerindias a una idea de que el náhuatl es la "lengua de los indios" $y$ por tanto, con esta lengua puede accederse o relacionarse con cualquier comunidad autóctona o encontrar documentos sobre cualquier región. Por ejemplo, algunos estudiantes creían que podrían usar esta lengua en regiones mayances como Yucatán o tomaban el curso a falta de cursos de quechua, pues aspiraban a ser andinistas. En todo caso, el náhuatl se concibe y valora como lengua "exótica" y "arcaica" asociada a un determinado marco geográfico y sociohistórico, como restos fósiles del patrimonio lingüístico que quedó disperso después de un proceso de castellanización que se cree temprano y completo. A ello contribuye una extrema distancia social, que no permite borrar estos prejuicios, ni que el estudiante imagine conocer a un nahuahablante y menos conversar con él. Los pocos que consideran viajar a México y trabajar con grupos autóctonos, no creen que la comunicación con ellos se vaya a hacer con esa lengua. En esto se descubre una distancia ideológica (prejuicio lingüístico) conformada por un imaginario nacional (español o mexicano) que presupone que la lengua náhuatl ya no se habla o, en otras palabras, la comunidad nahua ya (solo) habla español. De este modo, se estudia como si fuera una lengua muerta, literaria, antigua, etnográfica. Así surge una situación paradójica, pues si por un lado parece que el valor que se pone a la lengua contradice el sentido minorizado de la comunidad nahuahablante desde una reducción de la distancia psicológica, esto no parece deberse o encaminarse a una reducción de la distancia social.

Aunque se reconozca una diversidad y particularidad lingüística, no se acepta la necesidad de conocer y manejar en cierto grado la L2 como medio de relacionarse con el otro. Pareciera que se neutraliza la minorización y se normaliza el uso de una L2, aunque sea minoritaria, pero su aparente falta de vitalidad (habría que decir mejor visibilidad o reconocimiento), no plantea el contacto con el grupo de L2 como un proceso de aculturación, aunque se piense que conocer la lengua ayude a conocer la cultura. Así, la mayoría no ven en este aprendizaje un medio para contactar o visitar al grupo nahuahablante o para socializarse con él. Por tanto, parece que nos encontramos con una contradicción, pues si priman los motivos instrumentales y los motivos integradores, estos no apuntan a priori a un contacto directo con la comunidad nahua, entonces, ¿en dónde se quieren integrar los aprendientes? 


\section{El náhuatl como acceso a comunidades imaginadas}

Sea como LME o LMN, el que la lengua náhuatl sea la antonomasia de la indianidad supone, para el caso español, representar al otro, y en el mexicano al nosotros o al nuestro, hacia lo que se encamina el aprendiente cuando decide aprender la lengua. Así, el conocimiento de la lengua para el estudiante español es una puerta de entrada al otro, al otro suyo, mexicano, indígena, autóctono, ancestral. Se trata de conocer la cultura del otro, pero esta profundización distante es solo eso, lograr conocimiento, no tanto ser lo que se quiere conocer. Este mero interés informativo (traductivo-comprensivo) se hace incluso más obvio pues ni siquiera se espera un interlocutor.

Por tanto, el aprendiente siente que la lengua más bien le transporta, le hace identificarse, acercarse y encarnarse en el pasado. En ese caso, el estudiante español parece dejarse llevar por una arqueofilia, una arqueotreia o fascinación por lo antiguo (como los estudiantes de latín y griego, por ejemplo). El estudiante mexicano también lo puede vivir así, pero además como una progonoplexia u obsesión por los ancestros indígenas (sean o no nahuas). Esto no significa solo identificarse con los antiguos aztecas y revivir sus ceremonias, creencias y cosmovisión, sino incluso subrayar una especie de vacío o pérdida familiar al reafirmar su vocación en el hecho de haber tenido un abuelo o bisabuelo hablante de náhuatl (u otra lengua indígena). Es, por tanto, más que una orientación integradora, una orientación reintegradora guiada por una afectividad que busca un yo coherente identificado con ser nahuatlato. Acceder a este curso se vive como una oportunidad para revertir procesos de abandono, desplazamiento u omisión de la dimensión lingüística autóctona.

Este afán, más motivado por la vivencia que por el conocimiento, nos lleva a otras comunidades imaginadas surgidas del nacionalismo lingüístico mexicano y que pretenden incorporar una esencia (fundada en el atributo de lengua) y para nada persigue un fin comunicativo. Precisamente vemos que no se habla de regresar o ingresar a una comunidad nahua, se habla de entrar en una verdadera mexicanidad donde se integran las culturas madre del ser mexicano. Se parte de ese concepto de mestizaje que desde el discurso nacionalista antropológico, desde el siglo XIX ha tratado de superar las contradicciones internas con el mito fundacional de la nación que hace del grupo nahua un protagonista histórico privilegiado. Sin embargo, no se puede considerar a este tipo de estudiante de náhuatl un neohablante, pues, aunque pueda compartir su sentido de reivindicación, lo dirige más bien a dotarse de un rasgo de identidad "auténtica" enajenado, y su "ruptura" cultural no lo lleva hacia una efectiva muda lingüística, pues no se considera necesario su uso comunicativo pleno, y por tanto no aspira a ser un bilingüe activo. Así, muchos de estos estudiantes buscan conocer la lengua, pero no hablarla, pues ni identifican una comunidad de habla "vital" o "auténtica", ni aspiran a constituirse en una comunidad neohablante. Se queda así en un nivel de fantasía o falso neofalantismo (cfr. Ramallo, 2020: 240, 245). ${ }^{2}$

2 Este aspecto se constata también en el trabajo de Yoltzi Nava (2021: 148-168), donde podemos encontrar perfiles que permiten reconocer neohablantes, como el de tlahtolilnamikinih o recordantes, o el wehka ewanih o extranjeros. Los tlahtolilnamikinih son nahuas cuyo desarrollo de la lengua se vio dificultado o interrumpido en la niñez, o su lengua familiar ya fue predominantemente el español, por lo 
Así, más que querer ser reconocido como miembro, quiere verse como heredero de la cultura nahua. Se trata de reforzar una pertenencia, una identidad. Esta aspiración de congruencia etnolingüística es una forma de fortalecer un yo cuya autodeterminación implica hacer visibles aspectos invisibilizados, reprimidos o no promocionados, o al revés, ahora valorados, exhibidos y externados. Este "alejamiento" o "acercamiento" identitario parece responder al concepto de mestizo indigenista (Villoro, 2014), el cual frente al grupo nahua minorizado no se enfrentaría tanto a él, sino que se reconocería en él a sí mismo, manifestándolo en la acción (Villoro, 2014: 244-245). En este sentido, querer aprender la lengua náhuatl sería un acto de reivindicación, pero también de distanciamiento de un otro que "toma la figura de explotador extranjero o criollo". Esta negación del otro supone construir un yo que trata de resolver contradicciones identitarias y donde se siente parte de una comunidad imaginada donde las distinciones y desigualdades han desaparecido (Villoro, 2014: 246). Por tanto, el querer ser visto como parte de la comunidad nahuahablante más bien significa que rechaza serlo de una comunidad hispanocéntrica. Por consiguiente, no puede decirse que haya una actitud xenófila, pues no hay un verdadero interés por ser o participar del otro, sino una actitud autoctonófila que, a diferencia del caso del aprendiente que valora un nosotros y aspira a reintegrar un atributo revalorizado de su grupo étnico, valora un lo nuestro.

Esta aparente orientación re-integradora o des-integradora también nos lleva a otra razón integradora observada y no siempre expresada, que se haya subyacente en las motivaciones instrumentales mayoritarias: sentirse parte de un grupo especial. Ya se aludió a esto desde su manifestación como motivaciones intrínsecas, pues es un objetivo tácito. El náhuatl como lengua de trabajo, objeto de estudio o herramienta de investigación es un medio de comunicación o referencia entre especialistas, es decir, se aspira a ser parte del grupo de estudiosos de la lengua náhuatl y todo lo que ella representa como campo de conocimiento.

Por tanto, este marco de profesionalización explica que los aprendientes destaquen motivos instrumentales como una exigencia de especialización del conocimiento, como una oportunidad de salvar las carencias del plan de estudios o de aprovechar alternativas que no habían considerado en su currículo. Siguiendo la clasificación de Vallerand, incluso en aquellos casos donde estudiaran la lengua por recomendación de algún académico, se trataría, como en el caso español, del resultado de una regulación identificada, pero también de una regulación introyectada entre los estudiantes de antropología en cuanto que su plan de estudios establece

que tratan de recuperar, activar y actualizar su lengua originaria, viendo en la enseñanza de la lengua un recurso de compensación para desarrollar habilidades comunicativas básicas (habla, escucha, lectura, escritura), no solo para ser proficiente sino para certificar y dotar a su condición de hablante de cierto prestigio intelectual. Obviamente, ellos sí conocen y reconocen una comunidad de habla y por tanto pueden constituirse en comunidad de práctica aun en un medio urbano. En cuanto a los wehka ewanih, toman la lengua como recurso para poder interactuar con los nahuahablantes, asumiendo una configuración pluricultural y multilingüe de México, por lo que ser nahuahablante se ve como un requisito para relacionarse con ellos y sentirse integrados en la sociedad mexicana. Sin embargo, entre los hispanohablantes es raro encontrar esta aspiración; al menos en los grupos aquí estudiados no se aprecia dicha realización, quizá por lo ya señalado o depender de una motivación secundaria. 
que estudie una lengua indígena dentro de una oferta variada pero limitada, y en tal caso, aunque se asuma por la persona la necesidad de conocer una lengua. Por tanto, la autodeterminación del aprendiente refleja una motivación intrínseca por desarrollar una competencia técnica-profesional para desvelar significados culturales, y con ello encarnar un ideario profesional que en ocasiones representa el docente como especialista en una disciplina, donde conocer esta lengua le da autoridad como experto.

Este sentido iniciático y profesionalizante se ve acentuado por ser una oferta formativa no habitual que se muestra como un plus que puede marcar la diferencia, haciendo o sabiendo lo que los demás no saben, más aún si se siente la vocación de ser experto en la cultura, historia y literatura nahua. Así, es fácil, a partir de otros comentarios y experiencias, entender qué "yo" es el que articula esta experiencia de aprendizaje y el tipo de comunidad en la que se inserta y cobra significatividad. Ante todo, responde a la asunción de una imagen de especialista tanto temático como humanista, en cuanto que se prima el acceso a la fuente original y el contacto con el pueblo originario como garantía de seriedad, autenticidad y significatividad en el conocimiento y la interpretación-traducción cultural, y, si se ofrece, el contacto con el otro, pero desde la prudente distancia etnográfica. Así, es un yo profesionista que implica ser reconocido como miembro de una comunidad científica de excelencia y competencia. Se trata así de reproducir el ideario del "antropólogo" omnisciente y autónomo, el etnógrafo de campo y el etnohistoriador que rehúye las traducciones mismas o ajenas y es capaz de consultar directamente las fuentes y testimonios. Por tanto, paradójicamente, la orientación integradora no responde a una inserción en un grupo de L1 nativo, sino en un grupo de L2 estudioso de esa lengua o que estudia fenómenos culturales a través de la L2.

\section{Conclusiones}

La autodeterminación en el estudio de una L2 minorizada se ve orientada en el caso del náhuatl por el objetivo de construir un yo social marcado por una orientación xenofílica o autoctonofílica si la L2 se considera lengua materna o lengua nacional. En este caso, nos lleva a los procesos ya identificados en otros casos (Kim, 2007) donde el aprendizaje de una L2 se muestra también como un proceso de negociación, afirmación o negación de identidades por el aprendiente. A este respecto, no se considera un proceso de aculturación como tal, pues la construcción de una identidad o una identificación a partir de una LM como el náhuatl no responde a un proceso de acomodación a una lengua hegemónica o predominante ni a un proceso migratorio a la comunidad nahua, ni siquiera a vivir en un contexto multilingüe (visible). Así, en grupos de L2 que manifiestan poca o ninguna vitalidad etnolingüística (o son invisibilizados), su importancia social no descansa en las características sociolingüísticas del grupo de $L 2$, sino en los atributos con una elevada significación simbólica y política que el grupo de L1 proyecta sobre él.

En otras ocasiones, la motivación integradora -si puede seguir llamándose así- no dispone de un grupo meta o responde a una imagen o representación del grupo meta idealizada. Este 
imaginario distante se hace más evidente cuando se enfoca como lengua histórica y, en ese caso, se puede incluso hablar de fenómenos de arqueomanía, arqueofilia o arqueotesia, por los cuales se evidencia un gusto por lo antiguo que se advierte sobre todo en un acercamiento más definido hacia el náhuatl antiguo o clásico frente a otras propuestas más modernas o dialectales. En esto pesa la consideración de una variante más formalizada, estandarizada, extendida, escrituraria y en sí más cercana al náhuatl hablado por las civilizaciones históricas y cultivado en el virreinato. Por otra parte, también se descubre un fenómeno de progonoplexia por todo aquello que se identifique con sus ancestros míticos, tanto por reconocerse descendiente familiar como por identificarse con el imaginario lingüístico nacional e indigenista, fuertemente nahuacéntrico.

Otras veces esta decisión, como orientación integradora, no parte necesariamente de que los sujetos se sientan inmersos en un contexto multilingüe como sostenían Clément y Krudinier (1983). Este acercamiento evocativo o nostálgico no parte de que el estudiante reconozca el multilingüismo de su contexto inmediato o de México, ni siquiera el contacto con miembros del grupo L1, como ocurre con los neohablantes de otras regiones (Ramallo, 2020). Precisamente, la convivencia con esta lengua que no existe en los ámbitos urbanos mexicanos ni españoles, en el primer caso por la invisibilidad y en el segundo por la distancia. Así, ese multilingüismo se vive más como anticipación o evocación de espacios de pureza rural o de florecimiento histórico. Esto explica también el interés por el trabajo documental y las prácticas de lectoescritura, al margen de que, tras su elección, durante las clases se les muestre otro panorama.

El ver el aprendizaje de esta L2 como una lengua nacional y no como una lengua extranjera, no supone entre los estudiantes que se esté adoptando una international posture, como acontece con el estudio del inglés, precisamente por definirse minorizadamente como una lengua local, pero en su revalorización al menos estarían con su reapropiación dando pie a adoptar una national posture o una bicultural posture, a semejanza de lo que ocurre con los estudiantes indonesios de inglés (Lamb, 2004; 2009) y húngaros (Dörnyei, Csizér, 2002).

Entre los hispanohablantes españoles, un impulso xenofílico animaría a que el acercamiento a esta lengua también suponga cuestionar o salirse de la representación monolingüe de la comunidad hispánica. Desde esta perspectiva perciben en este aprendizaje la apertura y acceso a una comunidad-otra conectada, pero que por su carácter minoritario y local recalca un sentido glocal en cuanto que circunscriben la movilidad al ámbito nacional mexicano o a una comunidad imaginaria alternativa que representa la indianidad americana. Por otro lado, los hispanohablantes mexicanos manifestarían algo inversamente parecido, pues si se considera que su pertenencia a la comunidad hispánica les confiere una dimensión global, el conocimiento de la lengua náhuatl les ayuda a asumir o resaltar su sentido local o nacional. Esto implica que el aprendizaje de una L2 no siempre supone ser objeto de un proceso de "nacionalización" o "desnacionalización", como tradicionalmente se concebía desde los imperialismos lingüísticos 
y culturales y el principio establecido de la forma lingüística interior como rasgo definidor de un "ser" nacional (Moreno, 2008: 186-188) y describe otros procesos en los que la L2 ayuda a cuestionar la mirada minorizadora hacia representaciones plurales.

Puede pensarse así en una reacción contra la globalización y el mercado internacional de las lenguas, pero evidentemente todo surge de la existencia de oportunidades de contacto y aprendizaje que en ocasiones derivan de ese mismo proceso de globalización o al menos de mayor circulación de información y posibilidades de contactos comunicativos y de movilidad académica, profesional, turística, etc. Así, este caso se escapa de los mecanismos o circuitos de difusión e imposición de segundas lenguas como formas de imperialismo cultural o lingüístico (Phillipson, 1992; Moreno, 2015) y parecen propiciar identidades supranacionales o transnacionales en el sentido pluricultural o multicultural. No obstante, el querer propiciar estas identidades, sea como autoafirmaciones del yo o como identificación con una comunidad imaginada, no implica necesariamente esperar/querer ser aceptado o reconocido como miembro de una comunidad etnolingüística. Si el concepto de integratividad guarda un paralelo con los procesos de identificación que surgen durante el aprendizaje de la L1, un proceso "extended to a whole ethnolinguistic community" (Gardner, Lambert, 1972: 12), sería consecuente y coherente que haya una asociación entre identidad etnolingüística e identificación social como meta (lograr ser hablante supone poder sentirse o ser visto como miembro del grupo sociocultural), construyendo un autoconcepto bicultural, intercultural o transcultural. Aquí el proceso muestra a este tenor un deseo atenuado o restringido.

Mientras los grupos étnicos minoritarios se comunican en un segundo idioma, adoptan códigos lingüísticos y patrones de habla particulares en su comportamiento intergrupal (Dörnyei, Ushioda, 2009: 2) y muestran una predisposición e interés por interactuar con miembros de otros grupos (Gardner, Maclntyre, 1993: 159), en el caso de grupos étnicos mayoritarios esta orientación integradora no implica en sí esta predisposición. Aunque pudiera afirmarse que el aprendiente de náhuatl "must be willing to identify with members of another ethnolinguistic group and take on very subtle aspects of their behaviors" (Gardner, Lambert, 1972: 135), habría que pensar en otros modos de orientación integradora, tal como planteaban Dörnyei y Ushioda (2009: 2) en cuanto que ese deseo no se fija en un grupo meta ni se dirige hacia un grupo de hablantes específico. Así, la integratividad "no necesariamente atañe a ningún tipo de integración real en nada, sino que, en la mayoría de los casos, hace referencia a la integración metafórica" (Dörnyei, 2008: 82), es decir, tiene más que ver con una autoafirmación personal y poner al servicio de esta una determinada comunidad imaginada sobre la base de la lengua como su rasgo definitorio.

Si tomamos al náhuatl como caso ilustrativo, el aprendizaje de lenguas locales y minorizadas no se ajustan en estricto sentido a las dinámicas sociolingüísticas y psicoeducativas que suelen describirse en los estudios sobre aprendizaje de $L 2$, que se centran en lenguas extranjeras no minorizadas. Mientras que las lenguas internacionales, como las variedades del World 
English, son adquiridas por aprendientes con una fuerte motivación integradora "reflecting a sincere and personal interest in the people and culture represented by the other group" (Gardner, Lambert, 1972: 132), en el caso de las lenguas locales y además minorizadas, puede afirmarse que también existe ese sincero y personal interés, pero no necesariamente implica una actitud participativa y apropiadora, pues sus fines instrumentales responden a su posible aplicación profesional, en la generación de perfiles específicos y en lograr la aceptación en ámbitos disciplinares especializados.

Por otra parte, y como se señaló, su orientación integradora, aun dirigiéndose al grupo de L1, no implica necesariamente una aculturación por la relación asimétrica de poder y, en nuestro caso, la condición de bilingüismo ventajosa para el hispanohablante, además del estigma social asociado a lo "indígena". Esto tiene sus implicaciones en aspectos tales como la relación entre motivación y logro, incluso para el mantenimiento de la motivación inicial, que es la que tratamos. Por ende, sería interesante y quedaría pendiente saber cómo incide la experiencia misma de aprendizaje (profesor, currículo, didáctica, relaciones con compañeros) en estos casos, como se analiza en los casos generales (Dörnyei, Ushioda, 2011; Csizer, Kálmán, 2019).

\section{Referencias}

Anderson, B. (1993). Comunidades imaginadas. Reflexiones sobre el origen y la difusión del nacionalismo. México: Fondo de Cultura Económica.

Barriga Villanueva, R. (1995). México, país plurilingüe. Inti, Revista de literatura hispánica, (42), 115-131.

Beebe, L. M. (ed.). (1988). Issues in Second Language Acquisition. Multiples Perspectives. Nueva York: Newbury House Publishers.

Byram, M. (1997). Teaching and Assessing Intercultural Communicative Competence. Clevedon: Multilingual Matters.

Clément, R. (1980). Ethnicity, Contact and Communicative Competence in a Second Language. En Giles, H.; W. P. Robinson; P. Smith (eds.). Language: Social Psychological Perspectives. Oxford: Pergamon Press, 147-154.

Clément, R. (1986). Second Language Proficiency and Acculturation: An Investigation of the Effects of Language Status and Individual Characteristics. Journal of Language and Social Psychology, 5(4), 271-290. https://doi.org/10.1177/0261927X8600500403

Clément, R.; Z. Dörnyei; K. A. Noels (1994). Motivation, Self-Confidence, and Group Cohesion in the Foreign Language Classroom. Language Learning, 44(8), 417-448.

https://www.psych.ualberta.ca/ knoels/personal/Kim\%27s\%20publications/ClementDornyeiNoels1994.pdf 
Clément, R.; B. G. Kruidenier (1983). Orientations in Second Language Acquisition: I. The Effects of Ethnicity, Milieu and Target Language on their Emergence. Language Learning, 33(3), 272-291. https://doi.org/10.1111/j.1467-1770.1983.tb00542.x

Colás, M. P.; L. Buendía (coords.) (1998). Investigación educativa. Sevilla: Alfar.

Coller, X. (2005). Estudio de casos. Madrid: Centro de Investigaciones Sociológicas.

Csizér, K.; C. Kálmán (2019). A Study of Retrospective and Concurrent Foreign Language Learning Experiences: A Comparative Interview Study in Hungary. Studies in Second Language Learning and Teaching, 9(1), 225-246.

https://pressto.amu.edu.pl/index.php/ssllt/article/view/18556

Deci, E.; R. M. Ryan (1985). Intrinsic Motivation and Self-Determination in Human Behaviour. Nueva York: Plenum.

Dörnyei, Z.; E. Ushioda (eds.) (2009). Motivation, Language, Identity and the L2 Self. Clevedon: Multilingual Matters.

Dörnyei, Z. (2008). Estrategias de motivación en el aula. Barcelona: Editorial UOC.

Dörnyei, Z.; K. Csizér. (2002). Some Dynamics of Language Attitudes and Motivation: Results of a Longitudinal Nationwide Survey. Applied Linguistics, 23(4), 421-462. https://doi.org/10.1093/applin/23.4.421

Doughty, C. J.; M. H. Long (eds.) (2003). The Handbook of Second Language Acquisition. Oxford: Blackwell Publishing.

Figueroa Saavedra, M. (2007). Enseñanza de la lengua náhuatl como segunda lengua: problemáticas y buenas prácticas. Reporte técnico. México: SER, CIESAS.

Flores Farfán, J. A. (2017). Pasado, presente y futuro de las lenguas originarias de México. Un esbozo lingüístico. Zeitschrift für Romanische Philologie, 133(4), 973-997. https://doi.org/10.1515/zrp-2017-0051

Gardner, R. C. (1985). Social Psychology and Second Language Learning: The Role of Attitudes and Motivation. Londres: Edward Arnold.

Gardner, R. C.; W. E. Lambert (1959). Motivational Variables in Second Language Acquisition. Canadian Journal of Psychology, (13), 266-272. https://doi.org/10.1037/h0083787

Gardner, R. C.; W. E. Lambert (1972). Attitudes and Motivation in Second Language Learning. Rowley: Newbury House Publisher.

Gardner, R. C.; P. D. Maclntyre (1991). An Instrumental Motivation in Language Study: Who Says it Isn't Effective? Studies in Second Language Acquisition, (13), 57-72.

https://petermacintyre.weebly.com/uploads/1/0/1/8/10187707/motivation language1991.pdf

Giles, H. (ed.) (1977). Language, Ethnicity and Intergroup Relations. Londres: Academic Press.

Giles, H.; J. Byrne (1982). An Intergroup Approach to Second Language Acquisition. Journal of Multilingual and Multicultural Development, (1), 17-40.

https://doi.org/10.1080/01434632.1982.9994069 
Giles, H.; R. Y. Bourhis; D. M. Taylor (1977). Towards a Theory of Language in Ethnic Group Relations. En Giles, H. (ed.) Language, Ethnicity and Intergroup Relations. Londres: Academic Press, 307-348.

Giles, H.; P. Johnson (1981). The Role of Language in Ethnic Group Relations. En Turner, J.; H. Giles (eds.). Intergroup Behavior. Chicago: University of Chicago Press, 199-243.

Giles, H.; P. Johnson (1987). Ethnolinguistic Identity Theory: A Social Psychological Approach to Language Maintenance. International Journal of the Sociology of Language, (68), 69-99. https://doi.org/10.1515/ijsl.1987.68.69

Heath, S. (1992). La política del lenguaje en México. México: Instituto Nacional Indigenista.

Henmon, V. (1929). Some Significant Results of the Modern Foreign Language Study. The Journal of Educational Research, (19), 79-91. https://doi.org/10.1080/00220671.1929.10879920

Kim, Y. (2007). Ideology, Identity and Intercultural Communication: An Analysis of Differing Academic Conceptualizations of Cultural Identity. Journal of Intercultural Communication Research, (36), 237-253. https://doi.org/10.1080/17475750701737181

Lamb, M. (2004). Integrative Motivation in a Globalizing World. System, (32), 3-19. https://doi.org/10.1016/j.system.2003.04.002

Lamb, M. (2009). Situating the L2 Self: Two Indonesian School Learners of English. En Dörnyei, Z.; E. Ushioda (eds.). Motivation, Language Identity and the L2 Self. Bristol: Multilingual Matters, 229-247.

Markus, H.; P. Nurius (1986). Possible Selves. American Psychologist, 41(9), 954-969. https://doi.org/10.1037/0003-066X.41.9.954

Markus, H.; P. Nurius (1987). Possible Selves: The Interface between Motivation and the Self-Concept. En Yardley, K.; I. Honess (eds.). Self and Identity: Psychosocial Perspectives. Oxford: John Wiley \& Sons, 157-172.

Moreno, J. (2008). El nacionalismo lingüístico. Una ideología destructiva. Barcelona: Península.

Moreno, J. (2015). Los dominios del español. Guía del imperialismo lingüístico panhispánico. Madrid: Editorial Síntesis.

Muñoz, H. (2009). Comunidades lingüísticas e identidades colectivas minorizadas: de la protección y del reconocimiento a los derechos culturales. Confluenze, 1(1), 220-239. https://doi.org/10.6092/issn.2036-0967/1426

Nava, Y. (2021). El aprendizaje del náhuatl en el contexto urbano de Xalapa. Análisis de práctica de enseñanza-aprendizaje conducentes al diálogo intercultural. Tesis de maestría. México: Universidad Veracruzana.

Noels, K. A.; L. G. Pelletier; R. Clément; R. J. Vallerand (2000). Why Are You Learning a Second Language? Motivational Orientations and Self-Determination Theory. Language Learning, 50(1), 57-85. https://doi.org/10.1111/1467-9922.53223 
Noels, K.; T. Yashima; R. Zhang (2011). Language, Identity and Intercultural Communication. En Jackson, J. (ed.). The Routledge Handbook of Language and Intercultural Communication. Londres: Routledge, 52-66.

O'Rourke, B.; F. Ramallo (2018). Identities and New Speakers of Minority Languages: A Focus on Galician. En Smith-Christmas, C.; N. O'Murchadha; M. Hornsby; M. Moriarty (eds.). New Speakers of Minority Languages. Linguistic Ideologies and Practices. Londres: Palgrave Macmillan, 91-109.

Phillipson, R. (1992). Linguistic Imperialism. Oxford: Oxford University Press.

Ramallo, F. (2020). Neofalantismo y el sujeto neohablante. En Martín, L; J. Pujolar (coords.). Claves para entender el multilingüismo contemporáneo. Zaragoza: Editorial UOC y Universidad de Zaragoza, 229-265.

Amorrotu, E.; M. Puigdevall; F. Ramallo (2019). ¿Qué supone ser neohablante de una lengua minorizada? En Ramallo, F.; E. Amorrortu; M. Puigdevall (eds.). Neohablantes de lenguas minorizadas en el Estado español. Madrid: Iberoamericana-Vervuert, 7-21.

Rodrigo, M. (1997). Elementos para una comunicación intercultural. Revista CIDOB de Afers Internacionals, (36), 11-21. https://www.cidob.org/ca/articulos/revista cidob d afers internacionals/elementos para una comunicacion intercultural

Ruiz Olabuénaga, J. (2003). Metodología de la investigación cualitativa. Bilbao: Universidad de Deusto.

Schumann, J. (1978a). The Acculturation Model for Second Language Acquisition. En Gingras, R. (ed.). Second Language Acquisition and Foreign Language Teaching. Arlington: Center for Applied Linguistics, 27-50.

Schumann, J. (1978b). Social and Psychological Factors in Second Language Acquisition. En Richards, J. (ed.). Understanding Second and Foreign Language Learning. Rowley: Newbury House Publishers, 163-178.

Schumann, J. (1986). Research on the Acculturation Model for Second Language Acquisition. Journal of Multicultural and Multilingual Development, 7(5), 379-392.

https://doi.org/10.1080/01434632.1986.9994254

Siegel, J. (2003). Social Context. En Douhghty, C.; M. Long. The Handbook of Second Language Acquisition. Oxford: Blackwell Publishing, 178-223.

Vallerand, R.; L. Pelletier; M. Blais; N. Brière; C. Senécal; E.Vallières (1992).The Academic Motivation Scale: A Measure of Intrinsic, Extrinsic, and Amotivation in Education. Educational and Psychological Measurement, (52), 1003-1017. https://doi.org/10.1177/0013164492052004025

Vallerand, R.; L. Pelletier; M. Blais; N. Brière; C. Senécal; E. Vallières (1993). On the Assessment of Intrinsic, Extrinsic and Amotivation in Education: Evidence on the Concurrent and Construct Validity of the Academic Motivation Scale. Educational and Psychological Measurement, (53), 159-172. https://doi.org/10.1177/0013164493053001018 
Vallerand, R. (1997). Toward a Hierarchical Model of Intrinsic and Extrinsic Motivation. En Zanna, M. (ed.). Advances in Experimental Social Psychology, 29, 271-360. San Diego: Academic Press.

Villoro, L. (2014). Los grandes momentos del indigenismo en México. México: Fondo de Cultura Económica.

Woolard, K. A. (1989). Double Talk: Bilingualism and the Politics of Ethnicity in Catalonia. Stanford: Stanford University Press.

Yashima, T.; L. Zenuk-Nishide (2008). The Impact of Learning Contexts on Proficiency, Attitudes, and L2 Communication: Creating an Imagined International Community. System, (36), 566585. http://dx.doi.org/10.1016/j.system.2008.03.006 